\title{
Histological changes associated with an artificial anterior cruciate ligament
}

\author{
M Barry, S M Thomas, A Rees, B Shafighian, M A S Mowbray
}

\begin{abstract}
Aims-To investigate the histopathological features of the synovial lining of the knee following implantation of an artificial cruciate ligament.

Methods-Eighty two patients underwent anterior cruciate ligament reconstruction for chronic, symptomatic instability of the knee. The cruciate ligament was reconstructed with a scaffold type prosthetic ligament. All patients underwent arthroscopy at the time of cruciate reconstruction and also as a "second look" procedure at a mean 26.5 months later, at which time synovial biopsy specimens were obtained in all cases.
\end{abstract}

Results-The most frequent histological finding was granulomatous synovitis in $48 \%$ (39/82) of patients. Particulate polyester debris produced a greater response than carbon fibres. In $24 \%$ (20/82), nonspecific inflammation was present and in $28 \%(23 / 82)$ the synovium was considered normal. When the prosthetic ligament was fully covered by soft tissue in-growth, a granulomatous reaction was present in $42 \%$ (24/57), irrespective of whether the ligament was partially or totally uncovered. Stabilisation of the joint did not prevent subsequent deterioration in the articular cartilage; other factors such as increasing patient age, interval between injury and reconstruction and altered knee kinematics after reconstruction are probably important. Granulomatous synovitis was not associated with progressive chondral changes.

Conclusions-Although present in $48 \%$ of cases, granulomatous synovitis was not shown to have adverse effects on either chondral surface or the prosthetic material of the ligament. Rupture of the implant is caused by mechanical factors and granulomatous synovitis is not responsible for implant failure.

(f Clin Pathol 1995;48:556-559)

Keywords: Prosthetic cruciate ligament, arthroscopy, granulomatous synovitis, chondral damage.

The use of a prosthetic ligament for the reconstruction of a ruptured anterior cruciate ligament in the knee joint is controversial. An artificial cruciate ligament has a number of advantages including a lack of the donor site morbidity that may be seen after autologous reconstructions, ${ }^{1-3}$ rapid postoperative re- habilitation, shorter operative times, and a reproducible implant design. A frequent concern in the orthopaedic community is the presence of synovitis in association with prosthetic material within the knee joint, ${ }^{45}$ and whether this has any long term adverse effects on the knee. In particular, the presence of particulate debris with the subsequent development of a chronic granulomatous synovitis with enzymatic damage to the articular surfaces of the knee has been raised. ${ }^{6}$ Our paper attempts to address this issue.

\section{Methods}

Between 1986 and 1993, 277 patients underwent surgery for chronic, symptomatic instability of the knee. Of these 277,82 patients underwent arthroscopy at the time of cruciate

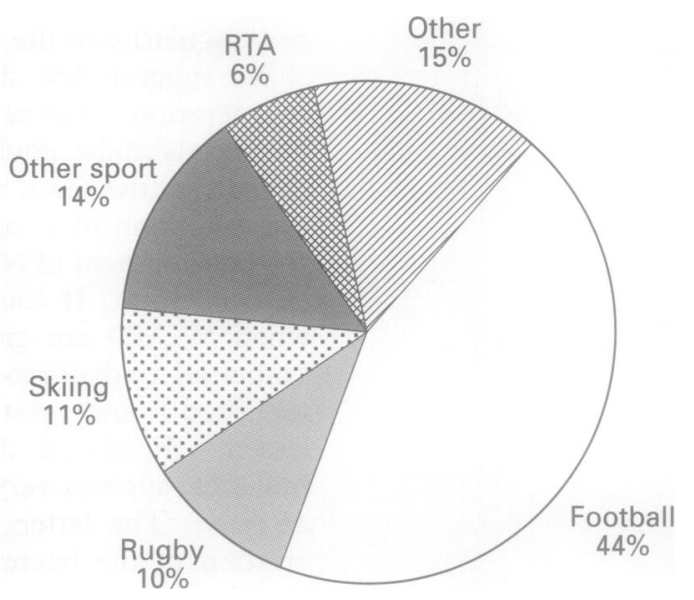

Figure 1 Cause of injury. RTA, road traffic accident.

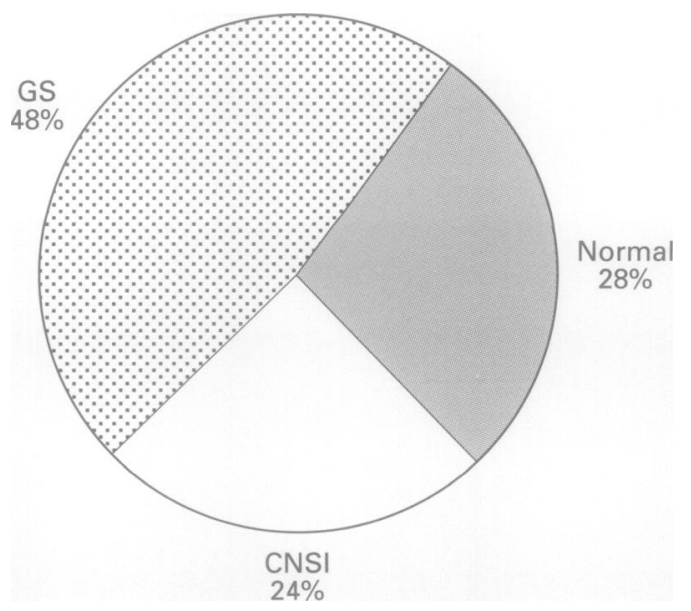

Figure 2 Histological appearance. CNSI, chronic nonspecific inflammation; $G S$, granulomatous synovitis. 


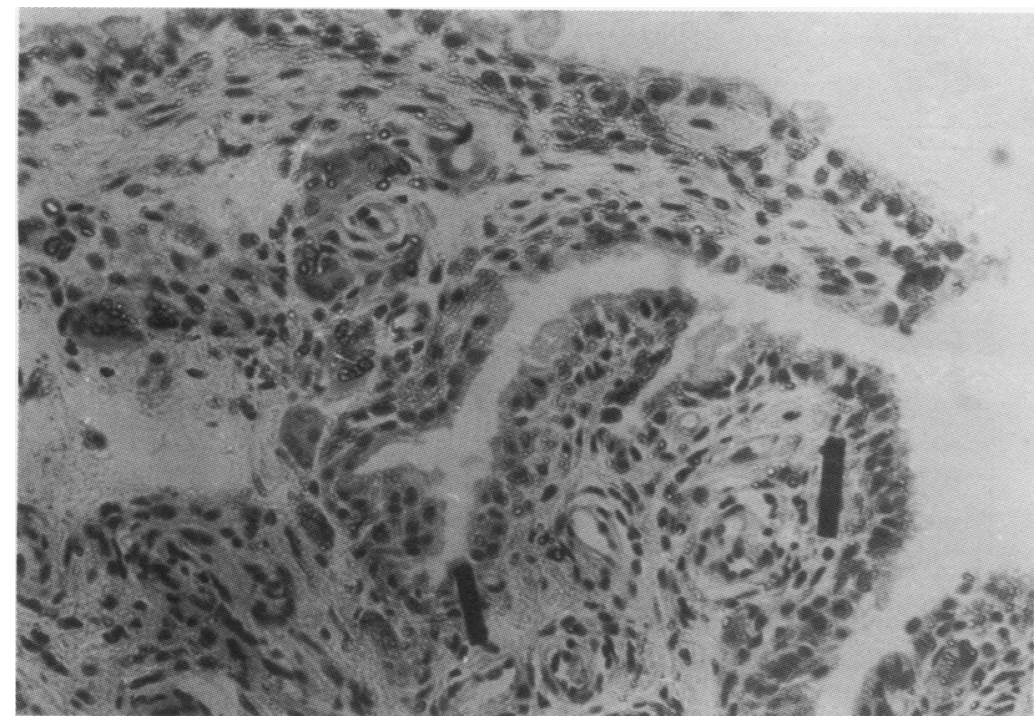

Figure 3 Synovial biopsy specimen showing chronic granulomatous synovitis associated with polyester fragments and carbon particles (haematoxylin and eosin; $\times 250$ ).

reconstruction and a further, "second look" arthroscopy at a mean of 26.5 months (range three to 76 months) after reconstruction. In all cases, a synovial biopsy specimen was taken at this second arthroscopy. None of these patients displayed evidence of a clinical synovitis.

This group of 82 patients were followed for a mean of 46.5 months (range $12-85$ months). There were $67(82 \%)$ male and $15(18 \%)$ female patients. The mean age at the time of surgery was $28 \cdot 2$ years (range 17-56 years) and the mean interval from injury to surgery was 34.4 months (range six to 132 months); $79 \%$ were sporting injuries. The cause of rupture is shown in fig 1.

Arthroscopic assessment was performed on all patients and the appearance of the chondral surfaces was noted. Chondral lesions were graded from 0 to $4:^{7}$ grade 0 , normal; grade 1 , softening or blistering of the articular surface; grade 2, presence of chondral fissures; grade 3 , deeper fissures extending to the subchondral bone; grade 4, exposure of the subchondral bone. An assessment of the cover of the implant

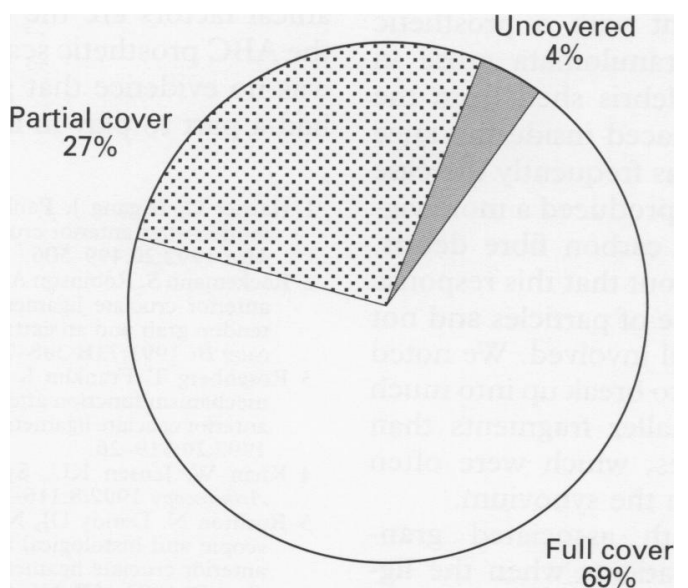

Figure 4 Ligament cover. was also made. Cover was graded as being full cover (no exposed prosthetic material), partial cover (some prosthetic material visable), or uncovered (whole implant seen).

Synovial biopsy specimens were taken from the supra-patella pouch and immediately placed in $10 \%$ formaldehyde. The specimens were subsequently processed through varying concentrations of industrial ethyl alcohol, cleared in xylene and embedded in paraffin wax. Sections $4 \mu \mathrm{m}$ thick were cut using a Basesledge microtome and stained with Cole's haematoxylin and eosin. The prepared specimens were then examined under the microscope using direct and polarised light.

Results were analysed using the unpaired Student's $t$ test and the $\chi^{2}$ test with Yates's correction if appropriate. Significance was accepted at the $\mathrm{p}<0.05$ level.

\section{ANTERIOR CRUCIATE RECONSTRUCTION}

All 82 patients had their anterior cruciate ligament reconstructed with a prosthetic ligament (ABC Ligament, Surgicraft, Redditch, UK). The ABC ligament is a scaffold class of prosthesis ${ }^{8}$ which promotes tissue in-growth and cover, providing a biologically stable implant. It is composed of 24 strands of unit material of either carbon fibre and polyester or polyester alone. ${ }^{9}$ In this series, 67 patients $(82 \%)$ had the carbon/polyester type and $15(18 \%)$ the polyester type.

\section{Results}

PATHOLOGY

The histological features of the synovial biopsy specimens obtained at the second arthroscopy are shown in fig 2 .

The most frequent histological finding in $48 \%(39 / 82)$ of cases was granulomatous synovitis. The giant cell reaction was found to be more vigorous in association with polyester rather than with the carbon particles (fig 3).

\section{THE PROSTHETIC LIGAMENT}

At arthroscopy, the ligament was found to be fully covered in $57(69 \%)$ patients (fig 4). In these patients granulomatous inflammation was found in 24 (42\%) cases. In the 25 patients with a partially or totally uncovered ligament a granulomatous reaction was found in 15 $(60 \%)$ cases. This difference is not significant.

In seven $(8 \%)$ cases the prosthetic ligament was found to have ruptured at the "second look" arthroscopy and granulomatous inflammation was found in five (71\%). In the 75 cases with an intact ligament granulomatous inflammation was found in $33(44 \%)$. This difference is not significant ( $p>0 \cdot 1, \chi^{2}$ test with Yates's correction).

\section{CHONDRAL LESIONS}

At the time of reconstruction, $15(18 \%)$ patients were found to have 16 (grades 2,3 or 4) chondral lesions. There was no significant difference in the mean age between those with 


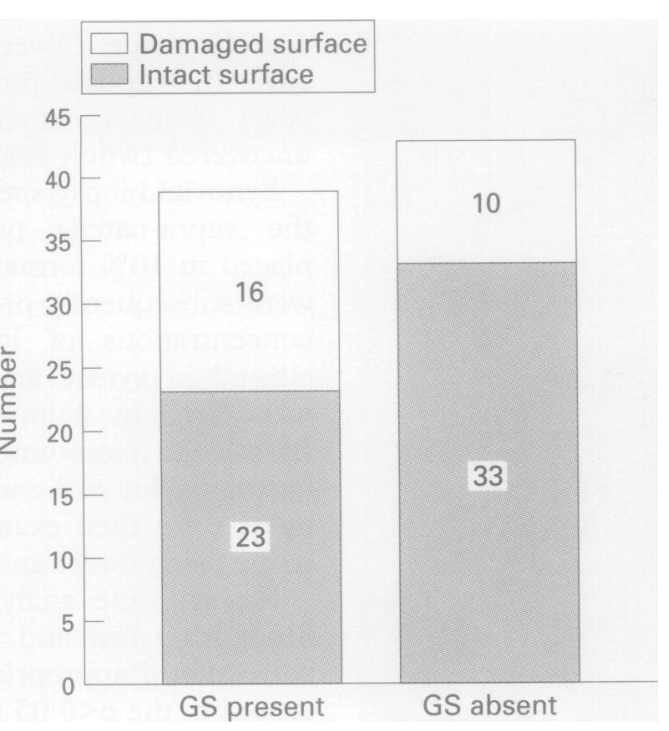

Figure 5 Status of chondral surface and associated histology. GS, granulomatous synovitis.

a chondral lesion ( $30 \cdot 2$ years) and those without ( $27 \cdot 8$ years). The mean interval from injury to surgery in the patients with chondral damage was 41.2 months, which was not significantly longer than those patients with an intact articular surface ( 32.8 months).

Of these 16 chondral lesions identified prior to reconstruction, nine (56\%) had resolved at the "second look" arthroscopy and the seven that were still present had all extended. However, also at this "second look" arthroscopy, 21 (26\%) patients were found to have 26 new chondral lesions.

When the presence of any chondral damage was related to the associated histology (fig 5), there was no statistically significant correlation between chondral damage and the presence of granulomatous synovitis ( $p>0 \cdot 5, \chi^{2}$ with Yates's correction).

\section{Discussion}

In this series $48 \%$ of patients had granulomatous synovitis at "second look" arthroscopy following reconstruction of their anterior cruciate ligament with a prosthetic scaffold implant. The granulomata arose in response to particulate debris shed from the artificial material once placed inside the knee joint. We found that it was frequently the case that particulate polyester produced a more vigorous response then the carbon fibre debris. Olsen $e t a l^{8}$ have pointed out that this response may be related to the dose of particles and not necessarily to the material involved. We noted that the polyester tended to break up into much more numerous and smaller fragments than the carbon fibre particles, which were often found lying inertly within the synovium.

Particulate debris with associated granulomata was found in patients when the ligament was fully covered. Shedding of debris will occur at the time of implantation, as the ligament is pulled through the tibial tunnel. Further shedding of particles may occur for a period of time before in-growth with biological tissue has occurred. Later, intermittent shedding of particles may occur if there is any degree of impingement of the implant. Impingement may lead to ligament rupture but the amount of debris shed at the time of ligament rupture is likely to be small. Mode of failure analysis ${ }^{10}$ has shown that ligament rupture is confined to a very limited area where it emerges from the tibial tunnel. There is no evidence of any long term (over five years) degradation of either the carbon or polyester fibres. Ligament rupture in our series has always been as the result of mechanical factors such as intra-articular graft impingement, fatigue, abrasion on sharp bony edges, or failure due to axial loading. We disagree with Prescott $e t$ al $^{11}$ that a granulomatous reaction in the ligament itself may be important in the pathogenesis of prosthetic rupture. This reaction is almost certainly the result of the rupture and not the cause.

A giant cell mediated granulomatous reaction in the synovium gives rise to concern particularly as there is a theoretical possibility that giant cell systems may produce chondrolytic enzymes harmful to articular cartilage. In our series, however, there was no statistical evidence that granulomatous synovitis was associated with progressive, widespread chondral damage. It is disappointing that successful postoperative stabilisation of the knee did not appear to prevent chondral wear and it is likely that other factors, such as age, interval between injury and reconstruction, subchondral bone injury at the time of cruciate rupture, ${ }^{12}$ and altered joint kinematics ${ }^{13}$ may account for the progressive deterioration in the articular surface of the knee joint after cruciate ligament reconstruction.

In conclusion, the appearance of a granulomatous reaction in the synovium of knee joints was noted in $48 \%$ of patients. Particulate polyester fragments produced a greater response than carbon fibres. There was no statistical correlation between progressive chondral wear in the knee joint and granulomatous synovitis. The increase in chondral damage noted arthroscopically was caused by other factors. Mode of failure analysis has shown that mechanical factors are the chief cause of failure of the ABC prosthetic scaffold. In this study there was no evidence that granulomatous synovitis had a part to play in implant rupture.

1 Harner C, Irrgang J, Paul J, Dearwater S, Fu F. Loss of motion after anterior cruciate reconstruction. $\mathrm{Am} \mathcal{F}$ Sport Med 1992;20:499-506.

2 Rackemann S, Robinson A, Dandy D. Reconstruction of the anterior cruciate ligament with an intra-articular patella tendon graft and an extra-articular tenodesis. $\mathcal{F}$ Bone foin Surg Br 1991;73B:368-73.

3 Rosenberg T, Franklin J, Baldwin N, Nelson K. Extenso mechanism function after patellar tendon graft harvest for anterior cruciate ligament reconstruction. Am 7 Sports Med 1992;20:519-26.

Klein $\mathbb{W}$, Jensen KU. Synovitis and artificial ligaments. Arthroscopy 1992;8:116-24.

Arthroscopy 1992;8:116-24.
Rushton N, Dandy DJ, Naylor CPE. The clinical, arthroscopic and histological findings after replacement of the scopic and histological findings after replacement of the anterior cruciate ligament
Surg $\mathrm{Br}$ 1983;65B:308-9.

6 Olson EJ, Kang JD, Fu FH, Georgescu HI, Mason GC, Evans $\mathrm{CH}$. The biochemical and histological effects of 
artificial ligament wear particles: In vitro and in vivo studies. Am f Sports Med 1988;16:558-70.

7 Outerbridge RE. The etiology of chondromalacia patellae. 7 Bone foint Surg Br 1961;43B:752-7.

8 Moyen B, Lerat JL. Artificial ligaments for anterior cruciate replacement. $\mathcal{F}$ Bone foint Surg Br 1994;76B:173-5.

9 Strover A, Hughes F, O'Brien T, Minns R. Mechanical properties of the $\mathrm{ABC}$ carbon and polyester fibre anterior cruciate ligament. In: Engineering in medicine. Proceedings of the Institute of Mechanical Engineering (UK). 1989:97-101.

10 McLeod A, Kong K, Mowbray M, Strover A, O'Brien T, Cooke W. Mode of failure analysis leading to new instrumentation for the enhancement of cruciate ligament reconstructive surgery. Proceedings of the 14th Congress of the International Society of Biomechanics; $1993 \mathrm{Jul}$ 10-14; Paris.

11 Prescott RJ, Ryan WG, Bisset DL. Histopathological features of failed prosthetic Leeds-Keio anterior cruciate ligaments. $\mathcal{f}$ Clin Pathol 1994;47:375-6.

12 Vellet AD, Marks PH, Fowler PJ, Munro TG. Occult posttraumatic osteochondral lesions of the knee: prevalence, classification and short-term sequelae evaluated with MR imaging. Radiology 1991;178:271-6.

13 Cawley PR. Is knee bracing really necessary. Knee bracing for ACL surgery; 1994 Jun 2; London. 